\title{
LOS PROBLEMAS METODOLÓGICOS DEL ESTUDIO DE LA INFLUENCIA EN LA LITERATURA COMPARADA
}

\author{
por Glyn M. HAMBROOK
}

En este articulo vamos a referimos principalmente a la "influencia» como concepto de la literatura comparada y, sobre todo, al aspecto de los estudios comparativistas que trata de la influencia de un escritor sobre otro. Este enfoque, aunque tratado principalmente del punto de vista literario, podria ser de interés, sin embargo, para todo tipo de historiador, ya sea del derecho, de la historia pura, del arte, de la filosofia, etc. (1).

Se ha discutido detenidamente y se sigue discutiendo el problema de la "influencia» desde un punto de vista teórico. Los teóricos de la critica literaria suelen plantear una serie de cuestiones claves: ¿Puede considerarse la "influencia» como un fenómeno visible manifestado concretamente en el mismo texto o se trata más bien de un procedimiento invisible e intangible que obra dentro de la conciencia del receptor de la influencia al provocar en éste alguna reacción un elemento determinado de la obra del emisor? ¿De donde procede la influencia, del emisor o de su obra? ¿O ambos se confunden, al ser ésta el único testimonio que existe de la sensibilidad o del pensamiento de aquél? Es más, sobre esta dimensión de la problemática se superpone otra, que se podria formular de la siguiente manera: la manifestación de la influencia ¿deberia buscarse, como hacian los positivistas iniciadores de la crítica llamada "cientifica", en las similitudes concretas, los "rapports de fait», entre dos textos, o en una esfera más vaga, más flexible,

(1) Conviene señalar aqui unos términos fundamentales de la literatura comparada a los cuales pensamos referirnos a lo largo del presente estudio. El termino aemisorn se emplea para referitse al escritor que "emites una influencia, o sea, que influye en otro escritor. I a "fuente" es chemento de la obra del cmisor de donde procede la influencia. I:I ueceptom es ytacn fecibe una inflencial y el areflejom es el festimonio de una influencia que se percibe en la obra del receptor. El reflejo sucle ser una similitud; es decir, un elemento más o menos extenso que se parece a otro elemento procediendo de una obra anterior. A veces se abusa de estos terminos tratando, por ejemplo, a un escritor como si fuera receptor o emisor antes de demostrar irrefutablemente o en la medida de lo posible que es asi su relación con otro autor anterior o posterior. Este abuso constituye otra faceta de la ambiguedad que conlleva el termino ainfluencian. 
más general, como la "tradición". Sin pretender menguar el valor de este planteamiento dialéctico con relación al problema de la ainfluencia", consideramos oportuno referirnos a un aspecto más o menos olvidado del problema de la influencia, una faceta que, sin embargo, mereceria un estudio más detenido por lo complejo y dificultoso de la misma. Nos referimos a la metodologia empleada en el estudio de la "influencia». Opinamos que es en este nivel práctico y no en el teórico donde radican las dificultades más empedernidas para el investigador.

Aunque quisiéramos cambiar de enfoque, dejando la polémica teórica para examinar la problemática metodológica, conviene tener en cuenta un aspecto teórico de la "influencia" que ha influido y sigue influyendo decisivamente en el tratamiento metodológico de esta cuestión: se trata del concepto de la causalidad. Como se puede sospechar, el término uinfluencian se ve ligado con mucha frecuencia a la noción de la relación causal. Este hecho es natural, no sólo porque la escuela positivista (finales del siglo XIX), de marcado carácter determinista, inició el estudio moderno de la influencia, sino también porque el mismo termino supone un efecto causal de una entidad sobre otra. Dado que el elemento causal que conlleva el concepto ainfluencia" implica una relación determinada entre una fuente y un receptor, seria de esperar que dicho término se limitase, en su aplicación, exclusivamente a aquellos casos donde existiese tal relación. Sin embargo, esto no es así, $y$ el término "influencian se utiliza con tal profusión y en tal variedad de contextos y situaciones que cabria preguntarse si se debe a la verdadera complejidad del procedimiento causal o más bien al abuso de un término que se presta a toda una gama de interpretaciones y, posiblemente, deformaciones. Así parece haberlo entendido lhab $H$. Hassan, quien, al referirse a esto, escribe:

"The concept is obviously called upon to account for any relationship. running the gamut of incidence to causality, with a somewhat expansive range of intermediate correlationss (2).

(“Es evidente que se recurre al concepto para explicar cualquier relación, desde la casualidad hasta la causalidad, y entre ellas una serie de correlaciones bastante extensas.")

Es más, Hassan precisa admirablemente cómo se explota esta variedad:

"Even among informed students of literature the subject has acquired a certain ambivalence, an ambivalence which is not entirely resolved by enclosing the word "influence" within guarded or ironic quotes" (3).

(2) Ihab H. HASSAN, "The Problem of Influence in Literary History: Notes

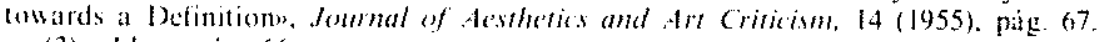

(3) lalem, pag. 66 . 
(«Aun entre los estudiantes de literatura más enterados. ef término hat ido adquiriendo cierta ambivalencia, una ambivalencia que no se resuelve completamente encerrando la palabra "influencia" entre comillas, de modo que éstas indiquen que se emplea aquélla con cierta ironia o inseguridad.,

Al mismo tiempo que hace hincapié Hassan en la incertidumbre con la cual se emplea el término, señala bien claro con la palabra "ambivalencia" to problemático que es la variedad de interpretaciones de la palabra "influencia», no sólo por esta diversidad de por sí, sino porque puede sugerirse $y$, por tanto, utilizarse, a la vez, más de una interpretación.

Una vez planteada esta problemática fundamental, podemos pasar al examen de otros factores que entran en el juego al nivel metodológico, teniendo en cuenta que desempeña la causalidad un papel de condicionante de éstos. Para empezar, conviene plantear la siguiente pregunta: ¿Cómo se puede elaborar una definición práctica de la influencia? $O$, más bien, ¿cuáles son los factores, si en realidad los hay, que tenderian a condicionar cualquier tentativo de definir en el nivel práctico el término objeto del presente estudio? Se trata, más o menos, de enfocar los presupuestos que suelen obrar en el critico a la hora de realizar un estudio de la "influencian. La primera tiene que ver con el hecho de que, al nivel metodológico, el crítico se ve atraido, sobre todo, por las similitudes concretas que ve entre una obra y otra, despertando estas semejanzas en él la conciencia de una posible relación causal. Esta atracción puede explicarse de la manera siguiente: al abarcar el estudio de la "influencia» se da por sentado que la influencia de un escritor puede verse, mejor dicho, que es un fenómeno que se manifiesta visiblemente y reviste una forma concreta al nivel del texto. Esta suposición se basa en otra, la que dice que no se puede estudiar lo que no se ve. Es más, interviene otro factor: la conciencia de las connotaciones de causalidad que conlleva el término uinfluencia» empuja al crítico a enfocar la semejanza concreta, al ser ésta el único medio por el cual se puede realizar o intentar la demostración de una relación causal auténtica. Sólo se puede demostrar la causalidad refiriéndose a datos precisos y dando ejemplos concretos. Por esa razón no se puede generalizar sobre la causalidad. Su comprobación tiene que ser precisa e irrefutable a base de datos concretos. De esta manera, es casi inevitable que al nivel metodológico el crítico se vea obligado a escoger un concepto teórico de la "influencia" que acepte que la influencia puede tener una forma visible. Si se rechaza este concepto, es casi imposible justificar el estudio. Hasta podriamos decir, por tanto, que no importa demasiado qué delimitación teórica se aplique a la "influencia", con tal que incorpore la aceptación de la causalidad visible, no porque la polémica teórica no tenga valor, sino porque las cuestiones que plantea ésta no surgen naturalmente en el nivel metodológico. Todo esto quiere decir que tampoco se puede prescindir de la similitud concreta, al ser ésta la forma por la cual la «influencia" se hace visible. 
Se facilita la elaboración de una definición práctica que sirva para iniciar el estudio de la relación existente entre facetas parecidas de dos obras al aceptar que la semejanza reviste una forma concreta en el nivel del texto. Considérese que la unidad básica del estudio de la «influencia» es la semejanza. En este caso, lo primero que al critico le toca hacer es apuntar todas las semejanzas que percibe, cualquiera que fuere su grado de similitud. Una vez acumulada esta materia prima, se trataria de separar las relaciones causales de las casuales ofortuitas. A la hora de abarear tal separación. las prioridades son tales que importa mucho más demostrar la causalidad que delimitar el concepto de la "influencia». Por esta razón parece lógico que una definición práctica del término se elabore a base de las pruebas de un lazo causal que existen y no a base del nivel donde ocurre la semejanza ni el grado de similitud entre la fuente y el reflejo.

Por consiguiente, convendria definir la unfluencias, por una parte, de una manera muy general; por ejemplo, como la reacción por parte de un escritor frente a la obra de otro, y, por otra parte. de una manera muy precisa, aplicando el término a sólo aquellos casos que diesen fe de la procedencia de tal reacción, o por ser tan obvia la fuente del reflejo o, mejor aún, al atribuir la semejanza el receptor a una fuente determinada (4). Un caso concreto de la sinfluencia" supondría. pues, un procedimiento de dos etapas: primero. el reconocimiento por parte del autor de un elemento de la obra del emisor como fuente de interés para él; segundo, el autor acoge este elemento reflejándolo en su propia obra y manifiesta abiertamente haber recibido esta influencia de un autor determinado. Por supuesto, este procedimiento multifacético de reconocer un elemento interesante, acogerlo y reaccionar a él, dando, al mismo tiempo, pruebas de su procedencia, no supone necesariamente que el reflejo recuerde la forma de ser de la fuente. Por minimo que sea el grado de similitud entre la fuente y el reflejo, cualquier alusión a la procedencia de la semejanza sigue constituyendo un caso de uinfluencia». Incluso son casos de influencia esos reflejos que no habrian recordado al critico una obra anterior si no hubiese existido una alusión explicita a ésta. Por estas razones, la «influencia» no depende del grado de similitud entre el reflejo y la fuente, sino de las pruebas que existen a favor de una relación causal.

Con esto llegamos a la problemática central que pretende abarcar el presente estudio: ¿Cómo debería proceder el critico frente a una semejanza (se trata generalmente de un grado de similitud bastante desarrollado) que no va acompañada de unas pruebas que manifiesten la existencia real de esa

(4) Aquí nos referimos a unos cjemplos muy concretos según los cuales un autor atribuye de una manera indudable la presencia de un elemento de su obra a la influencia de otro escritor. Esta atribución puede tomar muchas formas a veces nombra el receptor al emisor o le describe de tal manera que no deja lagar a dudas en cuanto a quién se refiere. 
fuente? Aquí nos referimos a aquellos casos en los cuales la afinidad podia proceder de varias posibles fuentes o incluso de ninguna, al ser el parecido. en este último caso. en la medida de lo posible totalmente aoriginalm. E] crítico se encuentra frente a una situación contradictoria: por una parte, no puede renegar de la afinidad que ha percibido; pero, al mismo tiempo, se encuentra en la imposibilidad de demostrar de una manera irrefutable que la existencia de esta misma afinidad se debe al conocimiento del receptor de una fuente determinada. De esta manera, al crítico le quedan dos opciones, la de dejarse convencer por la similitud, saltando así por encima de la falta de pruebas concretas, o la de respetar los datos tales como son, limitandose de esta manera a una hipótesis que no puede verificarse absolutamente. El problema, claro está, existe en el nivel de la exposición critica y abarca la cuestión de la ética critica. No es de extrañar que de esta tensión contradictoria nace una serie de abusos, porque es lógico que entre las posibles soluciones a la contradicción haya algunas engendradas por la conveniencia mas bien que por la honestidad. Para comprender de una manera más completa cómo y cuáles son estos abusos del razonamiento crítico, conviene considerar el conjunto de circunstancias que los engendran.

Dado que esta problemática metodológica se ve relacionada con aquellos casos donde existe una similitud, pero faltan pruebas de su procedencia, es evidente que se plantean las dificultades a la hora de intentar demostrar una relación causal, requisito imprescindible dadas las connotaciones que conlleva el término cinfluencian. La realidad es que la causalidad exige unas pruebas tan concretas como precisas, siendo las más idóneas las que permiten la identificación, sea directa o indirecta, por el receptor del emisor o, todavía mejor, la fuente precisa de la similitud. Luego vienen aquellas semejanzas que, a pesar de no estar acompañadas de un indicio concreto de su procedencia, se parecen tanto a la fuente que casi constituyen ejemplos del fenómeno comparativista de la imitación. En estos casos se trata, claro está, de unas pruebas más o menos concretas, sin las cuales se hace mucho más difícil la comprobación. Se trata ya de la esfera de la conjetura. En estos casos, es necesario muchas veces salir fuera del contexto inmediato dentro del cual ocurre el reflejo para buscar pruebas en otros sitios. Uno de los datos al que recurre con mucha frecuencia la crítica en busca de pruebas que respalden su conjetura es el conocimiento por parte del receptor de la obra de un escritor anterior a él. Nada mejor que esto para establecer la posibilidad de una relación causal. Hay que reconocer, sin embargo, que el mero hecho de haber leido a un escritor determinado no supone, sin embargo, el ser influido por él de tal manera que se ve la huella que deja su influencia. Si logró despertar el interés del receptor un elemento determinado de una obra anterior, ¿cómo se puede saber si esta influencia fue duradera o no? Es más, ¿cómo se puede deducir el mero hecho de que un escritor leyó a otro cuáles elementos de la obra de éste despertaron el interés de aquél, o qué clase de reacción provocaron? A pesar de todas estas consi- 
deraciones, basta muchas veces saber que un escritor leyó a otro para que el crítico saque la consecuencia de que todas las semejanzas con la obra anterior que se encuentran en la obli fosterior se explican por y se deben a esta lectura.

Aqui se ve claramente que la generalización sospechosa que hace el crítico se basa en su capacidad para asociar facetas parecidas por obras distintas y no en razones concretas. Lo que sirve admirablemente para elaborar una hipótesis muchas veces no contribuye nada a la elaboración de una comprobación irrefutable. Para convertir una conjetura en una certeza, hacen falta datos concretos que precisen el efecto de la lectura, señalando el efecto de elementos determinados de fuentes concretas, así como la manera de reaccionar del receptor a éstos. Tales datos los proporcionan a veces otras fuentes exteriores al texto; es decir, escritos biográficos o autobiográficos, entrevistas o incluso apuntes escritos al margen de las páginas de un libro, que precisan la influencia sobre el receptor de incluso un solo verso de poesia o una idea especifica y que, por tanto, constituyen el testimonio más seguro que hay de una relación causal. Otra prueba que también goza de bastante popularidad es la que proporciona un grado de similitud entre el reflejo y la fuente muy desarrollada, que, sin embargo, no es tan irrefutable como parecería a primera vista. La miga de duda radica en el hecho de que a veces se trata de lo que podríamos llamar una influencia escondida. Con esto nos referimos a un elemento de la obra del emisor que se debe a la influencia de otro emisor, pero cuya procedencia no se constató explícitamente por el autor influido. En este caso, el receptor acoge el elemento y lo refleja en su propia obra, sin saber que en realidad no procede del que le influyó, sino de otro emisor no-identificado anterior a éste. Cuando ocurre esto, el emisor posterior, el único emisor desde el punto de vista del receptor, es efectivamente un intermediario y no un emisor en el sentido auténtico de la palabra. Por esta razón cabria preguntarse hasta qué punto esta relación causal indirecta podria clasificarse de cinfluencia». Esta ambigüedad engendra la necesidad de tener en cuenta, en la medida de lo posible, todas las fuentes posibles, no sólo en el caso del receptor, sino en el caso del emisor, al ser éste casi más complejo que aquél.

Ahora bien, por una parte, aporta la casualidad la necesidad de unas pruebas rigurosas. Por otra parte, sin embargo, hay que considerar este rigor en relación con otro factor que coexiste con él dentro del conjunto de circunstancias que entran en juego al momento de abarcar el estudio de la "influencia». Este factor, que casi contrapesa las exigencias de la causalidad $o$ incluso se opone a ellas, es la dirección que quiere dar al estudio la similitud. Como hemos dicho ya, el reflejo, sea directo o indirecto, es la unidad básica del estudio de la «influencia». Además, podriamos definirla de la siguiente manera: es una similitud visible que existe entre una parte más o menos extensa de la producción literaria de un autor y una parte más 
( menos extensa de la obra de otro autor, existiendo al mismo tiempo anterior al primero. La cantidad de reflejos en un texto y la forma que toman dependen de un factor algo arbitrario: es decir, la capacidad del critico de percibir en una obra algo que le recuerda un aspecto o aspecto mas o menos determinados de una obra anterior. Esta capacidad funciona a hase de un procedimiento que se ve totalmente sometido a las leyes de la subjetividad; es decir, el de la asociación.

El critico reconoce o distingue un reflejo cuando conecta un parecido con un modelo, pero esta percepción puede variar, claro está, según una gama extensa de circunstancias tant o constitucionales (por ejemplo, la perspicacia natural del critico) como temporales (por ejemplo, el conocimiento del crítico de la obra del emisor tanto como el receptor, el número de escritores que el critico esta dispuesto a considerar como posibles emisores o receptores, una predisposición hacia un resultado determinado o, incluso, el estado mental o de salud del crítico a la hora de leer el material e iniciar el estudio). Es más ..... así se explica el valor especial que atribuye el critico al reflejo como unidad básica del estudio y por qué se considera imprescindible. la experiencia de percibir una asociación entre dos entidades es un fenómeno psicológico de indole intuitiva y, por tánto, una pequeña visión completa y sintética, una revelación lograda, positiva y significante. De esta manera, la intuición asociativa es una forma de consecuencia, con lo que el crítico no sólo se siente empujado a darle articulación en el nivel de la exposición crítica, sino que también tiende a volver a crear sus características más destacadas por medio del tono y la estructura de su interpretación. Dado que éstas proceden del hecho de que la intuición es una forma de consecuencia, resulta una expresión de tono decisivo, completo y afirmativo. Es más, en lo que se refiere al estudio de la "influencia", la manera más obvia y más natural de conseguir este fin seria por medio de la demostración de una relación causal, porque este método racionalizaria mejor que nada dentro del marco de la "influencia", no sólo la noción de una asociación, sino también, con las rigurosas pruebas que exige. lo acabado y lo sintético del procedimiento intuitivo que la acompaña. La intuición, junto con el cauce metodológico. crearian una doble obligación por parte del crítico, tanto la de reflejar la sintesis intuitiva de la asociación en el nivel de la expresión como la de demostrar una relación causal, tal como incumbirian las connotaciones del término «influencian.

Ahora bien, en este momento entra en juego el tercer factor que completa el conjunto de circunstancias que subyacen al estudio de la uinfluencia», tanto como los abusos de que éste puede verse contagiado. Se trata de lo que frustra la demostración de la causalidad, tanto como el impetu que engendran los reflejos. Nos referimos a la falta de pruebas de una relación causal. ¿Cómo reaccionan juntos los tres factores cuando se funden en el crisol de la conciencia del crítico? Sería de sospechar que la falta de pruebas anulase la posibilidad de demostrar la causalidad tanto 
como la de realizar la transposición de una sintesis asociativa en el nivel de la expresión, impidiendo de esta manera que el estudio siguiese adelante. Sin embargo, no es asi porque existe una manera de superar este obstáculo. Conviene recordar que cada demostración bien hecha está compuesta de dos elementos: unas pruebas decisivas y un tono (incluyente. Normalmente, va el uno estrechamente ligado al otro, puto separándolos y prescindiendo del primero, se satisfacen las exigencias de la causalidad y la asociación sin tener que someterse a la tirania de la prueba concreta. Este compromiso, o quizá deformación, se consigue bastante directamente, cambiando al tono concluyente yue proporciona una comprobación elaborada a base de hechos y datos concretos mediante la utilización de una retórica convenientemente elaborada, pero sin pruebas.

Cabe preguntar aquí por qué siguen con el estudio muchos criticos aun sabiendo que les faltan pruebas para comprobar su hipótesis. La única manera de explicar este fenómeno algo extraño es suponer que existe un impulso que obra en el critico, y que lo engendra el hecho de que cree desde el principio que el reflejo constituye un ejemplo de "la influencian. Es decir. la consecuencia del estudio no es un resultado al que se llega una vez realizada la investigación, sino que queda decidida de antemano, antes de llevar a cabo el trabajo. El origen de esta creencia podria explicarse por medio de la hipótesis siguiente: en cuanto vea el critico un reflejo, la fuerza de la intuición asociativa tiende a hacerlo resaltar de su contexto literario. aislándolo de lo que to rodea. Esta depuración del reflejo podría llevar a creer al crítico que se trata automáticamente de un caso de "influencia", que aqui se vería empleada en su sentido más general. Esta creencia irracional se reforzaria por medio de una volte face que produce el mismo término al surgir en la conciencia del critico. Las connotaciones de la noción junto con lo sintético de la asociación intuitiva que necesita reflejarse despiertan el recuerdo de causalidad, y en seguida la "influencia" se reduce a su sentido más estricto de relaciones causales demostrables. La promesa de la certeza existe desde el principio, y la tarea del crítico se hace la de realizarlo a todo precio. Si aceptamos esta hipótesis, nos permite explicar muchos factores que se ven en el desarrollo de la metodología del estudio de la anfluencia». Por ejemplo, se iría reforzando el procedimiento por el cual la atención critica enfoca exclusivamente y cada más intensamente el reflejo, de manera que éste se saca de su contexto y, como consecuencia, se reduce al mínimo la posible interferencia de otros elementos o posibles cuestiones criticas que procedan del mismo. Así se consolida la base de una retórica convincente, que tiene como requisito imprescindible el acuerdo del lector de que los parecidos señalados por el autor no sólo existen, sino que son usignificantes". En este caso el término "significante" quiere decir que existe la posibilidad de que estos parecidos representen un lazo causal, relación determinada con la cual ha identificado ya el crítico el reflejo. Se trata de contagiar al lector de la misma perspectiva 
que la del crítico. Para empezar, al nivel metodológico el critico tiene que orientar al lector hacia los reflejos apropiados, transponiendo sobre la estructura de su argamento el mismo procedimiento de aistamiento de similitudes y exclusion de interferencas que opero sobre su propia conciencia. Esta manipulación se consigue muy fácilmente por medio del estudio, en el que goza el crítico de un grado de control de material muy elevado mediante citas y la libertad de presentar sólo lo que a él le conviene. Una vez realizada esta transposición del procedimiento colectivo, que obró en el critico en el nivel de la exposición crítica, se ha demostrado más o menos la posibilidad de la anfluencia» (o sea, que los reflejos son «significantesm), y solo queda la tarea de convertir esta posibilidad en una apariencia de probabilidad. Se trata de organizar el contenido que se ha obtenido por el procedimiento de aislamiento de manera que su conexión con las fuentes a las cuales se semejan parece innegable. Aquí, claro esta. entra en juego la eficacia de la estructura retórica que elabora el critico a manera de argumento o estudio, dado que, como se ha dicho ya, donde faltan pruebas concretas hay que convencer con el tono mas bien que con el dato.

El procedimiento entero puede considerarse como compuesto de tres etapas principales, que son las siguientes:

1. Reconocimicnto de la similind. El critico percibe un reflejo, que enseguida desencadena el impulso de realizar la promesa de certeza que conlleva, tanto como el tono concluyente que exigen la causalidad y la transposición en el nivel de la expresión de la intuición asociativa sintética.

2. Justificacion de la posibilidad de lainfluencian. La demostración de la "significancia» del reflejo, que se consigue transponiendo el procedimiento del aislamiento del reflejo en el nivel del estudio.

3. Justificación de la probabilidad de ainfluencia". por medio de la reorganización de los reflejos abslados de su contexto. Aqui se asocian también con las fuentes a las cuales se parecen.

Queda bien claro que un argumento elaborado de esta manera sirve más que nada de un instrumento de persuasión que depende no solo de un contenido cuidadosamente escogido, sino de la ordenación de este. Como dice R. Humphris en uno de los poquísimos estudios sobre este aspecto de la metodologia de la literatura comparada:

"The validity of each individual inlluence argument depends on the logical validity of its internal structure and the fairness of the succession of the elements in it (its reasomableness)" (5).

(5) R. HUMPHRIS, "The Influence Argument". British Journal of Acsthetics, 10 (1976). pág. 265. Véase tambien. a proposito del problema de la influencia. SVEN

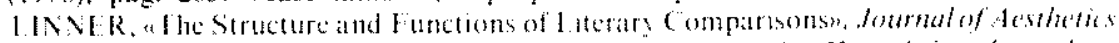
and art Criticism. 26 (1967-1968), pags. 169-179, a quien cita Humphris mas tarde a 
(«E) valor de cada argumento en pro de la influencia depende del valor logico de su estructura interna y lo justo de la ordenación de los elementos de que está compuesto (Jo razonable que es).")

No cabe duda de que según la metodologia que hemos analizado arriba sólo se supera la imposibilidad de demostrar una relación causal por falta de pruebas confiriendo al argumento un barniz de certeza igual al que tiene una exposicion critica basada en pruebas concretas. De este modo se hace pronto visible que el papel desempeñado por el crítico es más bien el de convencer que el de exponer; asi lo entiende Humphris, que dice a continuación:

"If we consider the influence argument, where no external evidence exists, the critic is trying to convince the reader that $A$ is a neccesary condition of 13 . that in all the multiple correlations involved that particular feature or combination of features is a vital one. He attempts to raise the status of his criteria to a level parallel to the necessary (rather than the merely sufficient) condition of the empirical argumentm(6).

("Consideramos el argumento en pro de la influencia: en un caso donde no existen prucbas externas, el critico está tratando de convencer al lector de que A sea una condición necesaria de $B$; que en todas las correlaciones múltiples presentes es ese elemento o esa combinación de elementos determimado ef mas importante. trata el critico de realizar el estado de sus cribrios a un nivel paralelo a la condición necesaria (más que la meramente suficiente) del argumento empirico.n)

A la hora de evaluar la metodología que hemos descrito arriba conviene recurrir a las normas de la ética científica que con más frecuencia se aplican a la convalidación de las técnicas de la crítica literaria. Entre aquéllas existe una según la cual son imprescindibles para la demostración de cualquier hipótesis unas pruebas concretas y es inválida toda afirmación que no se vea justificada a base de datos precisos. Esta norma califica ria de pecado critico cualquier estudio camuflase por debajo de un barniz de retórica una falta de pruebas irrefutables. Visto desde esta perspectiva, el mismo término "pecado" supone la necesidad de corregir o evitar un procedimiento, que, al medirse contra una regla ética, dio un resultado muy poco favorable. La imposibilidad de aceptar la metodologia tal como es no procede solamente, sin embargo, del hecho de que ésta ofende una norma cientifica. Toda norma aparte. hay que reconocer que las dos posibilidades o aproxima-

propósito de la necesidad de convencer al lector de la probabilidad de una influencia, y Haskell M. BLOCK. "I he Concent of Influence in Comparative Literature", Yearbook of Comparative and General Literature, 7 (1958), págs. 30-37.

(6) $k k^{\prime} m$, pág. 265. 
ciones criticas planteadas dentro de esta metodología -... o sea, el respeto a la causalidad o la obediencia al impulso engendrado por el reflejo--..-ocurren ambos de una manera natural y, por tanto, son ambos resultados críticos logrados en el sentido de que es capaz de engendrar cada uno una metodologia critica que responde plenamente a sus necesidades. El asunto no puede dejarse asi, sin embargo, porque aunque ambos sean procedimientos naturales son, al mismo tiempo, opuestos, al exigir uno unos datos concretos y el otro la falta de ellos. Que se aplique una norma para juzgar el valor de la metodología o que se consideren como resultados naturales de un conjunto de circunstancias las tendencias opuestas que encierra aquélla, queda el la tarea de resolver la problemática que plantea cada una. A la hora de decidir entre ellas, casi no queda más remedio que aplicar la norma del respeto a las pruebas, al ser ésta probablemente la única manera de efectuar la eliminación de una de las dos posibilidades. Cabria añadir, sin embargo, que la aplicación de esta norma no es tan fácil como pareceria. Decir que se trata simplemente de frenar el desarrollo metodológico que engendran las presupuestas despertadas por el reconocimiento del reflejo seria demasiado simple, aunque no hay que negar que tenga su parte de verdad. Hay que tener en cuenta que el punto de partida del estudio de la "influencia» es un impulso psicológico, y no se trata simplemente de una interpretación objetiva y desinteresada de los datos. Aún no seria inacertado sugerir que, en realidad, el argumento que suele elaborarse a favor de la «influencia» no tiene nada que ver con la comprobación de lazos causales, sino que responde a la promesa de la certeza y la necesidad de reflejar un estudio de sintesis en el nivel de la exposición crítica que conlleva el mismo impulso. De esta manera, cualquier tentativa de reforma critica tendria que superar no sólo una lógica errónea y dudosa, sino una reacción y procedimientos psicológicos, los cuales habrian encerrado dentro de su evolución el silogismo siguiente: si la base del estudio de la uinfluencia» es la similitud y si, al mismo tiempo, la similitud exige que se exprese por medio de un tono concluyente, entonces la (influencia» no vale la pena de estudiarse si no puede haber tono concluyente. Aquí hay que afrontar la consecuencia contradictoria según la cual la misma reforma crítica corre el riesgo de invalidar el estudio del concepto que pretende reanudar. Este peligro demuestra claramente lo necesarias que son unas series de prioridades, requisitos imprescindibles para cualquier intento de reforma critica. Primero, cualquier sustituto metodológico tendría que proporcionar unas posibilidades de canalizar el entusiasmo critico iguales a las que proporcionaba la metodologia anterior, y segundo, precisando un poco la primera exigencia, la sola hipótesis tendria que adquirir el grado o el estado de una consecuencia crítica valedera en si misma; es más, sería imprescindible que el critico creyese que habia realizado una tarea de notable importancia intelectual al saber evitar las afirmaciones que no fuesen respaldadas por pruebas concretas. De otro modo, la reforma crítica sólo podría seguir 
desempeñando el papel de impedimento usbstaculo a un impulso que, si no fuese por el hecho de que tendia a deformatse en la interprelacion. sería lotalmente acepable

Sin prefender haber resuello dedinitivamente una problemátiea que por sil diversidad acaso nunca puteda solucionatse de una ver, creemos, por lo menos, haber puesto al descubiento los factores yue entran en juego a la hora de poner en marcha un procedimento metodológico hasta ahora may poco estudado. Por tanto, acaso convenga terminar el presente estudio no con un resumen de la lrayectoria del trabajo, sino con otro planteamiento que no se ha discutido hasta ahora con el proposito de recordar al lector que incluso infreduciendo normas a criterios por los cuales se resuction o, por lo menos, se acharan algumos aspectos de la fecunda y profunda problemática que presental la sinfluenciam, la critica no llega a agotal por medio de tha sola firmula todas las posibles ramificar ciones engmaticas yene engendra este concepto tan fundamental dentro de esa dimension de la critica literasal yte se demomina la literatura comparada. Se trata de poner al descubierto otrat posible solución al problema central de este estudio que ha pretendido enfocar las reacciones criticas ocastonadas por ana falta de pruebas de lazos causales cuando obra éstat sobet el conjunto de circunstancias que nace al momento de concebir un estudio de la inflencia de un alutor sobre otro. Si despues de todo al crítico le parece yue no puede realizar un estudio tal, si se le prohibe introducir en a) un tono concluyente. siempre le queda la opeion de prescindir del obstaculo que surge ante sus ojos eada vez que se pone a articular los rellejos que percibe por medio de una lectura. Nos referimos a la mismat causalidad. Parece perfectamente razonable deshacerse de esta noción si el crítico está dispuesto a volver la espalda a las connotaciones implicitas que conlleva el término "inluencia" para elaborar una nueva definición de él. según la cual el concepto seria sinonimo de repetición de un elemento durante un plazo más o menos prectso. En este caso, la repetición del elemento se considetaría como una uradición y la "inllatencian trataria de la continudad y la evolución del elemento dentro de la tradición que había creado, sin que la causalidad entrase en juego. $Y$ en el caso en que apareciese alguna relación calusal demostrable, podría igualmente juntarse con los demás parecidos, al ser ayuéla simplemente una categoria más de similitud entre todas las existentes. Se opone a esta hexibilidad el razonamiento de que no se puede ignorar las connotaciones que conlleva el término «influencia” y que al eliminarlas pierde la palabra todo su sentido y, por tanto, su valor. Pero después de todo, si se expone claramente que se utiliza la "influencia" para referirse a la tradicion y no a unas relaciones causales. las connotaciones del término no tienen tanta importancia como la nueva definición que se le atribuye. Ademis, acaso tenga mis trascendencia el hecho de que al ser la metodologia que se basa en la "atadicion" una manera de normalizar el estudio de la "inlluencia" partiendo del impulso engen- 
Irado puramente por el reconocimiento del reflejo y no de la necesidad de espetar la causalidad, facilitaría la realización del tipo de estudio que whelan desarrollar muchos críticos al abarcar un tema de influencia. prescindiendo del mismo elemento (la causalidad) que ocasionaba la necesidad de cometer el "pecado" critico. 